\title{
Interstitial and Langerhans' dendritic cells in chronic periodontitis and gingivitis
}

\section{Patricia Ramos Cury ${ }^{(a)}$ Cristiane Furuse ${ }^{(b)}$ \\ Ana Elisa Amaro Rodrigues ${ }^{(c)}$ José Alexandre Barbuto(d) Vera Cavalcanti de Araújo(b) Ney Soares de Araújo(e)}

(a) PhD, Professor, Department of Microbiology; (b)PhDs, Professors, Department of Oral Pathology (c)Master's Degree Student - São Leopoldo Mandic Dental Reseach Center, Campinas, SP, Brazil.

(d) $\mathrm{PhD}$, Professor, Department of Immunology, Institute of Biomedical Sciences, University of São Paulo, São Paulo, SP, Brazil.

(e) PhD, Professor and Chairman, Department of Oral Pathology, School of Dentistry, University of São Paulo, São Paulo, SP, Brazil.

\section{Corresponding author:}

Patricia Ramos Cury

Laboratório de Cultura de Células,

Centro de Pesquisa Odontológica São

Leopoldo Mandic

Rua José Rocha Junqueira, 13, Ponte Preta

Campinas - SP - Brazil

CEP: 13045-610

E-mail: patriciacury@s/mandic.com.br

Received for publication on Jul 17, 2007

Accepted for publication on Nov 05, 2007

\begin{abstract}
The aim of the present study was to compare quantitatively the distribution of dendritic cell subpopulations in chronic periodontitis and gingivitis. Fourteen biopsies from patients with chronic periodontitis and fifteen from patients with gingivitis were studied. An immunoperoxidase technique was used to quantify the number of Langerhans' cells (CD1a) and interstitial dendritic cells (factor XIIIa) in the oral and sulcular and junctional/pocket epithelia and in the lamina propria. A greater number of factor XIIIa+ dendritic cells in the lamina propria and CD1a+ dendritic cells in the oral epithelium were observed in gingivitis compared to the periodontitis group $(\mathrm{p}=0.05)$. In the sulcular and junctional/pocket epithelia and in the lamina propria, the number of CD1a+ dendritic cells was similar in the gingivitis and periodontitis groups. In conclusion, the number of Langerhans' cells in the oral epithelium and interstitial dendritic cells in the lamina propria is increased in gingivitis compared to periodontitis, which may contribute to the different pattern of host response in these diseases.
\end{abstract}

Descriptors: Periodontitis; Gingivitis; Dendritic cells; CD1a; Factor XIIIa. 


\section{Introduction}

Gingivitis and periodontitis are characterized by distinct host responses. Although a great deal of information is available, the mechanism which regulates this difference is still poorly understood. Variation in host response against periodontopathogens is associated with genetics and environmental factors $;^{1}$ however, whether and how gingivitis will progress to periodontitis still has to be elucidated. It has been suggested that the progression is associated with more abundant Th2 cells than Th1 cells in chronic periodontitis, ${ }^{2}$ or with an increase in the number of B cells and plasma cells in periodontitis and predominance of $\mathrm{T}$ cells in gingivitis. ${ }^{3}$

Dendritic cells (DCs) represent a large family of antigen-presenting cells that circulate through the bloodstream and are scattered in nearly all tissues of the body. DCs serve as a connection between an innate immune system and an adaptive immune response, being the most potent antigen-presenting cells. They capture microbes and their antigens while in the immature state, and stimulate a T-cell response to these antigens in their mature state. DCs are the only antigen-presenting cells capable of priming naive helper/cytotoxic $\mathrm{T}$ cells to undergo clonal expansion, thus initiating an adaptive immune response. ${ }^{4}$ In their immature state (CD1a positive Langerhans' cells), DCs are efficient antigen capture cells and, as they mature, they undergo phenotypic changes that facilitate migration toward lymphoid organs and enable their ability to prime naive $\mathrm{T}$ cells in the context of MHC-II molecules. ${ }^{4}$ Besides stimulating $\mathrm{T}$ cell responses, a different subset of DCs (factor XIIIa positive interstitial DCs) also directly stimulate naive B cells to differentiate into plasma cells in vitro. ${ }^{5}$

The number of Langerhans' cells in gingival tissues is a topic of much speculation. Studies have reported increased numbers in periodontitis, ${ }^{6}$ de- creased numbers in gingivitis and periodontitis compared to healthy periodontal tissues, ${ }^{7}$ and no quantitative change in periodontitis compared to gingivitis and healthy periodontal tissues. ${ }^{8}$ On the other hand, little is known about the distribution of factor $\mathrm{XIIIa}+$ DCs and their possible role in periodontitis and gingivitis. Jotwani, Cutler ${ }^{9}$ (2003), evaluating 7 biopsies of chronic periodontitis and 5 biopsies of healthy gingival tissue, demonstrated that the number of factor XIIIa+ DCs is increased in periodontitis compared to healthy gingival tissue.

The present study aimed to compare quantitatively the distribution of Langerhans' cells (CD1a+) and interstitial DCs (factor XIIIa+) in chronic periodontitis and gingivitis.

\section{Material and Methods}

The study protocol was approved by the Ethics Committee, School of Dentistry, University of São Paulo, Brazil.

Biopsies were retrieved from the files of the Department of Oral Pathology, São Leopoldo Mandic Dental Research Center, and from those of the School of Dentistry, University of São Paulo. Fourteen biopsies from cases diagnosed as chronic periodontitis (mean age $=34.5 \pm 9.2$ years; $10 \mathrm{fe}$ male and 4 male) and fifteen from cases diagnosed as gingivitis (mean age $=32.9 \pm 8.9$ years; 9 female and 6 male), involving systemically healthy patients, were analyzed. The diagnoses were obtained based on clinical and histological examinations. For histological diagnosis, the sections were stained with hematoxylin and eosin.

Serial sections of $3 \mu \mathrm{m}$ in thickness were obtained from formalin-fixed paraffin-embedded tissue. Dewaxed sections were incubated with primary antibody. Clone, pre-treatment for antigen retrieval, dilutions, and incubation time are given in Table 1. Immunohistochemistry was performed on the sections

Table 1 - Antibodies, clones, target retrieval, dilutions, incubation times, and cell specificity of the primary antisera.

\begin{tabular}{c|c|c|c|c|c}
\hline Antibody & Clone & Antigen retrieval & Dilution & Incubation time & Cell specificity \\
\hline CDla & $010^{*}$ & Citrate buffer $0.1 \mathrm{M}, 95^{\circ} \mathrm{C}, 30$ minutes & $1: 100$ & 40 minutes & Langerhans' cells \\
\hline Factor XIIla & $\mathrm{Ab-1**}$ & No treatment & $1: 700$ & 40 minutes & Interstitial dendritic cells \\
\hline
\end{tabular}

*Dako Corp., Carpinteria, CA, USA. ${ }^{* *}$ Neo Markers, Fremont, CA, USA. 
using the biotin-streptavidin-peroxidase method, followed by developing in a diaminobenzidine chromogen solution. Finally, the sections were counterstained with Mayer's hematoxylin. All incubations were performed in a moist chamber at room temperature.

Omission of the primary antibody constituted the negative control. For the CD1a antibody, tonsil tissue was used as a positive control; for factor XIIIa, dermatofibroma was used.

The specimens were photographed with a microscope (Axioskop 2 Plus, Zeiss, Gottingen, Germany) at $400 \mathrm{X}$ magnification interfaced to a computer; the areas were delimited with mouse and measured with a specific software (Microsoft AxioVision 4.2, Carl Zeiss Vision GmbH, Gottingen, Germany).

Cell counts were performed in duplicate throughout the entire sections by two masked examiners. The number of immunolabeled cells per area unit (cell number $/ \mathrm{mm}^{2}$ ) was calculated for each primary antibody. Counts of CD1a and factor XIIIa positive cells were restricted to immunolabeled cells exhibiting a well-defined cell nucleus and body with at least two well-visualized dendrites. Three regions were evaluated: oral epithelium, sulcular and junctional/ pocket epithelia, and lamina propria (Figure 1).

The mean value of the counts of the two examiners was used for statistical analysis. Differences in the number of immunolabeled cells between the gingivitis and periodontitis groups were analysed using

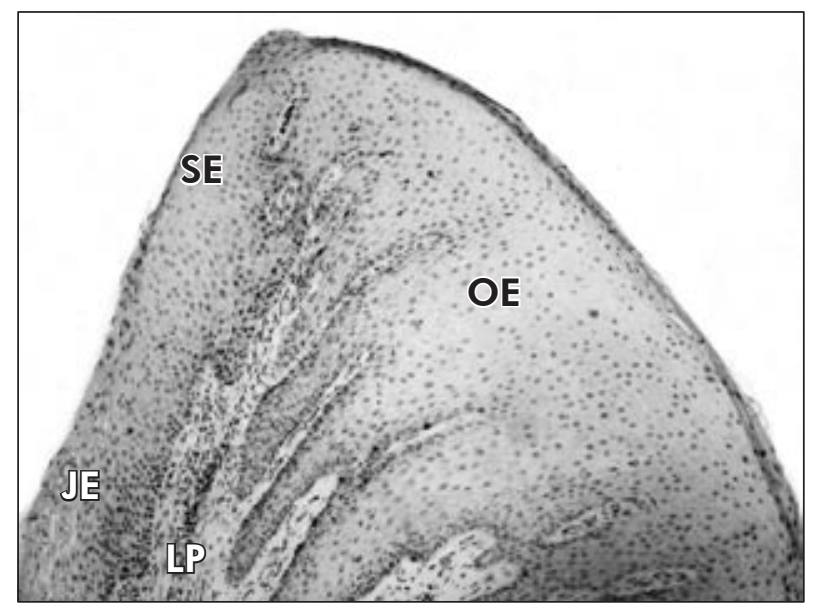

Figure 1 - Gingival counting zones: oral epithelium (OE), sulcular (SE) and junctional/pocket epithelia (JE), and lamina propria (LP). (Immunohistochemistry, CDla, $100 \mathrm{X}$ ). the Mann-Whitney U test. Statistical significance was defined as $p \leq 0.05$. Calculations were performed using a statistical software package (SPSS Inc., Chicago, IL, USA).

\section{Results}

Table 2 presents the mean number \pm standard deviation of CD1a+ and factor XIIIa+ cells $/ \mathrm{mm}^{2}$ in the oral epithelium, junctional/sulcular epithelia, and lamina propria in the gingivitis and periodontitis groups.

In the oral epithelium, the number of CD1a+ dendritic cells $/ \mathrm{mm}^{2}$ was significantly greater $(\mathrm{p}=0.05)$ in gingivitis than in periodontitis (137.69 \pm 90.36 and $74.09 \pm 74.75$ respectively) (Figures $2 \mathrm{~A}$ and $2 \mathrm{~B}$ ). In the sulcular and junctional/pocket epithelia and lamina propria, the counts of CD1a+ dendritic cells were similar in both groups.

A greater number of factor XIIIa+ dendritic cells in the lamina propria was observed in gingivitis compared to the periodontits group $(\mathrm{p}=0.05)$ $(209.49 \pm 101.26$ and $104.27 \pm 95.52$, respectively) (Figures 2C and 2D). No factor XIIIa+ dendritic cell was observed in the epithelia.

\section{Discussion}

The present study reveals significant differences in the number of CD1a+ cells $/ \mathrm{mm}^{2}$ in the oral epithelium and of factor XIIIa+ cells $/ \mathrm{mm}^{2}$ in the lamina propria between periodontitis and gingivitis, being the numbers increased in gingivitis.

The lower number of DCs in periodontitis compared to gingivitis may decrease the defense response

Table 2 - Mean number \pm Standard deviation of CDla+ and factor XIIla+ cells $/ \mathrm{mm}^{2}$ in the oral epithelium (OE), junctional/sulcular epithelia (JE), and lamina propria (LP) in the gingivitis and periodontitis groups.

\begin{tabular}{l|c|c|c|c}
\hline \multirow{2}{*}{ Antibody } & \multirow{2}{*}{$\begin{array}{c}\text { Counting } \\
\text { Zone }\end{array}$} & $\begin{array}{c}\text { Gingivitis } \\
(\mathrm{N}=15)\end{array}$ & $\begin{array}{c}\text { Periodontitis } \\
(\mathrm{N}=14)\end{array}$ & $\begin{array}{c}\mathrm{P} \\
\text { value }\end{array}$ \\
\cline { 3 - 5 } & OE & $137.7 \pm 90.4$ & $74.1 \pm 74.8$ & 0.05 \\
\hline \multirow{3}{*}{ CD la } & JE & $174.3 \pm 129.6$ & $116.8 \pm 137.9$ & 0.11 \\
\cline { 2 - 5 } & $\mathrm{LP}$ & $259.9 \pm 109.8$ & $278.6 \pm 180.9$ & 0.86 \\
\hline Factor XIIla & LP & $209.5 \pm 101.3$ & $104.3 \pm 95.5$ & 0.05 \\
\hline
\end{tabular}



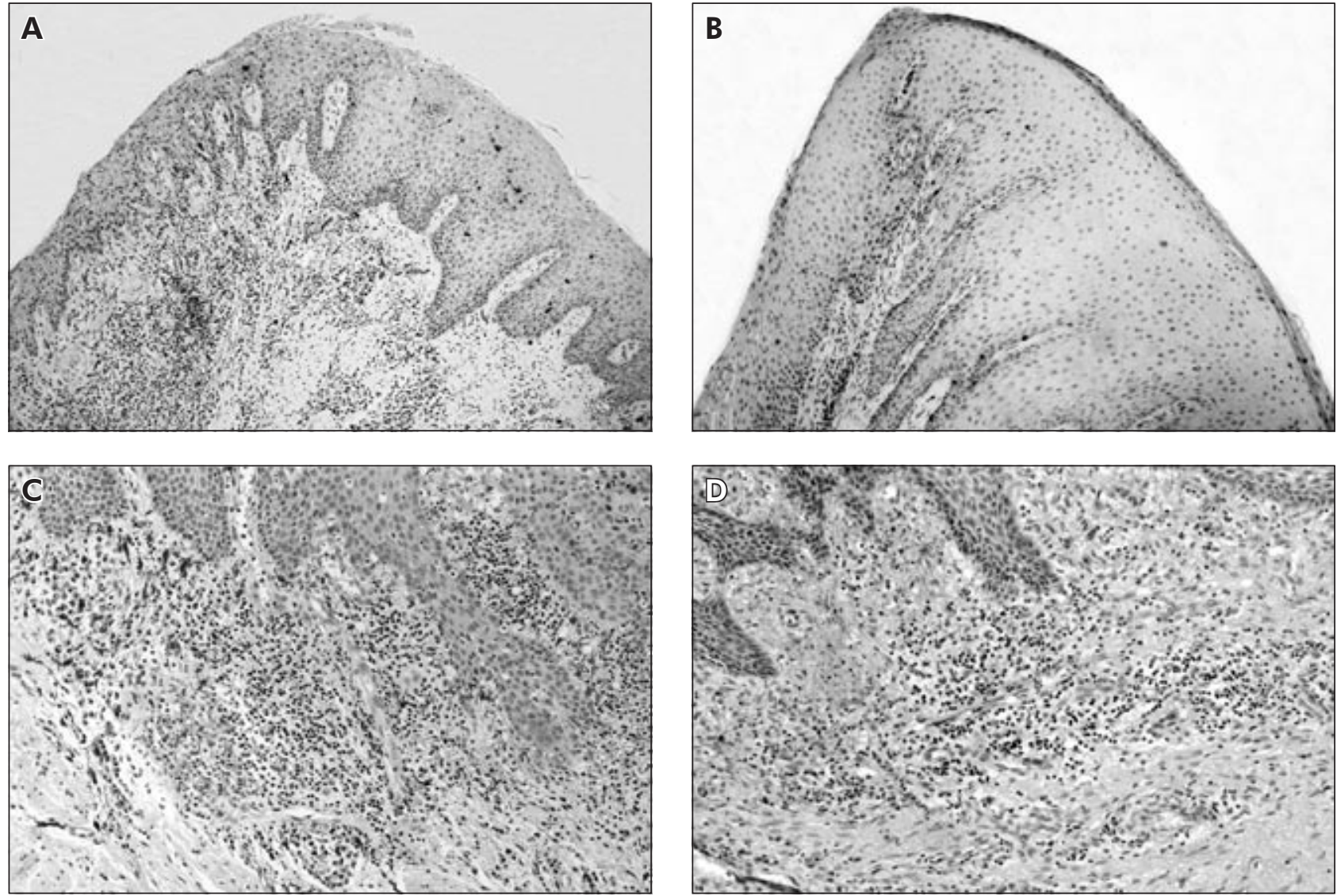

Figure 2 - CDla + dendritic cells in the oral epithelium. A - chronic periodontitis (Immunohistochemistry, 100 X); B - gingivitis (Immunohistochemistry, $200 \mathrm{X}$ ). In the oral epithelium, the number of CDla+ dendritic cells $/ \mathrm{mm}^{2}$ was significantly greater in gingivitis than in periodontitis. Factor XIIla+ dendritic cells in the lamina propria. C - chronic periodontitis (Immunohistochemistry, 400 X); D - gingivitis (immunohistochemistry, 400 X). A greater number of factor XIIla+ dendritic cells in the lamina propria was observed in gingivitis compared to the periodontitis group.

to periodontal bacteria, thus explaining the different patterns of disease. The differences in the number of DCs might be associated with several factors: 1 DC differentiation may be inhibited by certain periodontal bacteria. DC differentiation and maturation is inhibited by many infectious agents. It has been demonstrated that human monocytes cultured with granulocyte-macrophage colony-stimulating factor (GM-CSF) and interleukin-4 (IL-4) after phagocytosis of Candida albicans yeast do not differentiate into DCs; they retain CD14 expression, do not acquire CD1a expression, and are unable to express the maturation markers CD83 and CCR7. On the other hand, monocytes that had phagocytosed mycelial forms differentiate into mature CD83+ and CCR7+ cells. ${ }^{10}$ Similarly, M. tuberculosis down-regulates CD1a expression on DCs, ${ }^{11}$ and plasmodium infec- tion is also characterized by inhibition of DC function in vivo and in vitro. ${ }^{11} 2$ - DCs have captured the antigens and matured. Porphyromonas gingivalis lipopolysaccharide triggers maturation of DCs, ${ }^{12}$ thus immature DCs $(\mathrm{CD} 1 \mathrm{a}+)$ in periodontitis may have captured the antigens (Porphyromonas gingivalis) and maturated to present the antigens, ${ }^{6}$ and then a lower number of CD1a+ cells was observed in periodontitis. 3 - Patients with periodontitis may present a lower differentiation of DCs compared to patients with gingivitis, and this may increase the risk of progression of gingivitis to periodontitis. Further studies are required to evaluate these hypotheses.

The Langerhans' cell network seems to change markedly with aging ${ }^{13}$ and smoking habits. ${ }^{14}$ In this study the groups were age-matched. However, the information concerning the smoking habits was not 
available and further studies are required to assess the role of smoking.

It has been previously reported that although DC heterogeneity has been observed in humans, their lineage origins, maturation stages and functional differences have not been clearly established. Interstitial DCs, also known as dermal DCs, and Langerhans' cells are originated from a myeloid lineage. ${ }^{15}$ They are "immature" cells, i.e., are unable to stimulate $\mathrm{T}$ cells. Although these DCs lack the requisite accessory signals for T-cell activation, such as CD40, CD54 and CD86, they are extremely well equipped to capture antigens. After antigen capture, full maturation and mobilization of DCs are induced. In the epithelium, immature DCs known as Langerhans' cells are labeled for CD1a+. Langerhans' cells take up particles and microbes by phagocytosis, ${ }^{16}$ mature and move into lymphoid tissues ${ }^{17}$ or lamina propria ${ }^{6}$ in search of $\mathrm{T}$ cells for antigen presentation.

In the present study, the number of CD1a+ DCs/ $\mathrm{mm}^{2}$ in the oral epithelium was significantly higher in gingivitis compared to periodontitis. On the other hand, in the sulcular and junctional/pocket epithelia and lamina propria, the counts of CD1a+ DCs were similar in periodontitis and gingivitis. These results might be associated with a limited $\mathrm{T}$ cell count in periodontitis as compared to gingivitis. ${ }^{3}$ However, contrasting results have been shown in the literature regarding DC counts in periodontal diseases. Increased numbers in periodontitis, ${ }^{6}$ decreased numbers in gingivitis and periodontitis compared to healthy periodontal tissues, ${ }^{7}$ and no quantitative change in periodontitis compared to gingivitis and healthy periodontal tissues ${ }^{8}$ have been reported. The

\section{References}

1. Macêdo TCN, Costa MCN, Gomes-Filho IS, Vianna MIP, Santos CT. Factors related to periodontal disease in a rural population. Braz Oral Res. 2006;20(3):257-62.

2. Kinane DF, Lappin DF. Immune processes in periodontal disease: a review. Ann Periodontol. 2002;7(1):62-71.

3. Seymour GJ, Greenspan JS. The phenotypic characterization of lymphocyte subpopulations in established human periodontal disease. J Periodontal Res. 1979;14(1):39-46.

4. Banchereau J, Steinman RM. Dendritic cells and the control of immunity. Nature. 1998;392(6673):245-52. number of DCs changes markedly with aging and smoking habits, which may explain such divergent results. ${ }^{13,14}$

Cells that express CD34 contain progenitors for two discrete DCs populations: the epidermal Langerhans' cells and dermal or interstitial type of DCs. ${ }^{5}$ Factor XIIIa+ cells represent interstitial DCs ${ }^{4}$ which have major effects on B-cell growth and immunoglobulin secretion. ${ }^{4}$ Naïve B cells respond uniquely to the interstitial, non-Langerhans' cell type of DCs, and by secretion of soluble factors, the interstitial type of DCs stimulate the prodution of antibodies directly. One important functional difference between CD1a+ and factor XIIIa+ cells is that only interstitial-type DCs directly stimulate naïve B cells to make antibodies. ${ }^{5,18}$ In the present study, the number of factor XIIIa+ cells was greater in gingivitis than in periodontitis, indicating that factor XIIIa-positive cells may also play an important role in the periodontal disease pathogenesis. Jotwani, Cutler $^{9}$ (2003) have shown that the number of factor XIIIa+ DCs is increased in periodontitis compared to healthy gingival tissue.

\section{Conclusion}

In conclusion, the number of Langerhans' cells in the oral epithelium and interstitial DCs in the lamina propria is increased in gingivitis compared to periodontitis, which may contribute to the different pattern of host response in these diseases. However, the immune process is complex, and further studies controlling smoking habits and other host variables are required to reach a better understanding of the role of DCs in periodontal disease.

5. Caux C, Massacrier C, Vanbervliet B, Dubois B, Durand I, Cella M et al. CD34+ hematopoietic progenitors from human cord blood differentiate along two independent dendritic cell pathways in response to granulocyte-macrophage colonystimulating factor plus tumor necrosis factor alpha: II. Functional analysis. Blood. 1997;90(4):1458-70.

6. Jotwani R, Palucka AK, Al-Quotub M, Nouri-Shirazi M, Kim $\mathrm{J}$, Bell D et al. Mature dendritic cells infiltrate the T cell-rich region of oral mucosa in chronic periodontitis: in situ, in vivo, and in vitro studies. J Immunol. 2001;167(8):4693-700. 
7. Seguier S, Godeau G, Leborgne M, Pivert G, Brousse N. Quantitative morphological analysis of Langerhans cells in healthy and diseased human gingiva. Arch Oral Biol. 2000;45(12):1073-81.

8. Gemmell E, Carter CL, Hart DN, Drysdale KE, Seymour GJ. Antigen-presenting cells in human periodontal disease tissues. Oral Microbiol Immunol. 2002;17(6):388-93.

9. Jotwani R, Cutler CW. Multiple dendritic cell (DC) subpopulations in human gingiva and association of mature DCs with CD4+ T-cells in situ. J Dent Res. 2003;82(9):736-41.

10. Torosantucci A, Romagnoli G, Chiani P, Stringaro A, Crateri $\mathrm{P}$, Mariotti $\mathrm{S}$ et al. Candida albicans yeast and germ tube forms interfere differently with human monocyte differentiation into dendritic cells: a novel dimorphism-dependent mechanism to escape the host's immune response. Infect Immun. 2004;72(2):833-43.

11. Cutler CW, Jotwani R, Pulendran B. Dendritic cells: immune saviors or Achilles' heel? Infect Immun. 2001;69(8):4703-8.

12. Kanaya S, Nemoto E, Ogawa T, Shimauchi H. Porphyromonas gingivalis lipopolysaccharides induce maturation of dendritic cells with CD14+CD16+ phenotype. Eur J Immunol. 2004;34(5):1451-60.
13. Zavala WD, Cavicchia JC. Deterioration of the Langerhans cell network of the human gingival epithelium with aging. Arch Oral Biol. 2006;51(12):1150-5.

14. Robbins CS, Dawe DE, Goncharova SI, Pouladi MA, Drannik AG, Swirski FK et al. Cigarette smoke decreases pulmonary dendritic cells and impacts antiviral immune responsiveness. Am J Respir Cell Mol Biol. 2004;30(2):202-11.

15. Banchereau J, Briere F, Caux C, Davoust J, Lebecque S, Liu YJ et al. Immunobiology of dendritic cells. Annu Rev Immunol. 2000;18:767-811.

16. Svensson M, Stockinger B, Wick MJ. Bone marrow-derived dendritic cells can process bacteria for MHC-I and MHC-II presentation to T cells. J Immunol. 1997;158(9):4229-36.

17. Adema GJ, Hartgers F, Verstraten R, de Vries E, Marland G, Menon S et al. A dendritic-cell-derived C-C chemokine that preferentially attracts naive $\mathrm{T}$ cells. Nature. 1997;387(6634):713-7.

18. Fayette J, Durand I, Bridon JM, Arpin C, Dubois B, Caux C et al. Dendritic cells enhance the differentiation of naive $\mathrm{B}$ cells into plasma cells in vitro. Scand J Immunol. 1998;48(6):56370. 